\title{
Corydalis saxicola Bunting total alkaloids attenuate paclitaxel-induced peripheral neuropathy through PKCE/p38 MAPK/TRPV1 signaling pathway
}

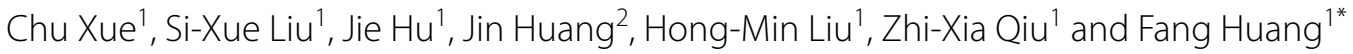

\begin{abstract}
Background: Corydalis saxicola Bunting, affiliated with the Papaveraceae Juss., has been proven to work well in antiinflammation, hemostasis, and analgesia. This study was designed to observe the effect and potential mechanism of Corydalis saxicola Bunting total alkaloids (CSBTA) on paclitaxel-induced peripheral neuropathy (PIPN).
\end{abstract}

Materials and methods: Rats were injected $2 \mathrm{mg} / \mathrm{kg}$ paclitaxel 4 times and administrated with $30 \mathrm{or} 120 \mathrm{mg} / \mathrm{kg}$ CSBTA. Mechanical and thermal allodynia and hyperalgesia were tested. After 40 days, serum was collected to detect PGE2, TNF- $\alpha$, and IL-1 $\beta$ by ELISA. The L4-L6 segment spinal cord, DRG, and plantar skin were harvested, and Westernblot or RT-qPCR analyzed protein and gene levels of pro-inflammatory cytokines, p38 MAPK, PKC $\varepsilon$, and TRPV1. The PIPN cell model was established with paclitaxel $(300 \mathrm{nM}, 5 \mathrm{~d})$ in primary DRG neurons. We examined the effect of CSBTA ( $25 \mu \mathrm{g} / \mathrm{ml}$ or $50 \mu \mathrm{g} / \mathrm{ml}$ ) by measuring the mRNA levels in PGE2, TNF- $\alpha$ and CGRP, and the protein expression on the PKCE/P38 MAPK/TRPV1 signaling pathway in the PIPN cell model.

Results: The results showed that CSBTA effectively ameliorated allodynia and hyperalgesia, and regulated cytokines' contents (PGE2, TNF- $a$, and IL-1 $\beta$ ) and neuropeptides (CGRP and SP) in different tissues in vivo. In addition, CSBTA significantly decreased cytokine gene levels of DRG neurons (PGE2, TNF- $a$, and CGRP) and the protein expressions of PKCE/P38 MAPK/TRPV1 signaling pathway in vivo and in vitro.

Conclusion: Therefore, CSBTA has a perspective therapeutic effect on the treatment of paclitaxel-induced peripheral neuropathy.

Keywords: Paclitaxel, Paclitaxel-induced peripheral neuropathy, Corydalis saxicola Bunting total alkaloids, DRG neurons

\section{Introduction}

Paclitaxel, extracted from Taxus brevifolia Nutt., is widely used to treat solid tumors, such as breast cancer, lung cancer, ovarian cancer [1]. It exerts anticancer

\footnotetext{
*Correspondence: huangfang@cpu.edu.cn

1 Jiangsu Key Laboratory of TCM Evaluation and Translational Research, Department of Pharmacology of Chinese Materia Medica, China Pharmaceutical University, 639 Longmian Road, Nanjing 211198, China Full list of author information is available at the end of the article
}

effects by increasing the stability of tubulin polymer and inhibiting the proliferation of cancer cells. However, paclitaxel-induced peripheral neuropathy (PIPN), serious side effects during paclitaxel treatment, severely limits its application in the clinic and is characterized by numbness, tingling, spontaneous pain, and temperature sensitivity. The incidence of PIPN significantly increases during long-term treatment, and this side effect will persist for months or years [2]. PIPN responds poorly original author(s) and the source, provide a link to the Creative Commons licence, and indicate if changes were made. The images or other third party material in this article are included in the article's Creative Commons licence, unless indicated otherwise in a credit line to the material. If material is not included in the article's Creative Commons licence and your intended use is not permitted by statutory regulation or exceeds the permitted use, you will need to obtain permission directly from the copyright holder. To view a copy of this licence, visit http://creativecommons.org/licenses/by/4.0/. The Creative Commons Public Domain Dedication waiver (http://creativeco mmons.org/publicdomain/zero/1.0/) applies to the data made available in this article, unless otherwise stated in a credit line to the data. 
to clinical analgesics such as opioid analgesics, anticonvulsants, or antidepressants [3]. There are no proper prevention and treatment measures, and the underlying mechanism is still unclear.

The molecular mechanisms of pathogenesis have been investigated recently. It is widely recognized that mitochondrial dysfunction is a significant contributor to PIPN. In addition, paclitaxel could promote cell damage by inhibiting tubulin depolymerization, interfering with the stability of microtubules (including neuronal axons), switching on mitochondrial permeability transition pore (mPTP), disturbing calcium signals in mitochondria and endoplasmic reticulum, and so on. The chemotherapeutic drug-induced inflammatory process is also considered a potential factor. The release of pro-inflammatory cytokines and chemokines is regarded as one of the main mechanisms of neuro-immune regulation $[4,5]$.

Currently, some studies have emphasized the role of transient receptor potential vanilloid type 1 (TRPV1) in the pathological progress of PIPN [6-8]. TRPV1, one of the nonselective cation channels, could be activated by heat $\left(43{ }^{\circ} \mathrm{C}\right)$, protons, and ligands (e.g., capsaicin) [6]. More and more studies have shown that TRPV1 is involved in the essential mechanisms associated with inflammatory and neuropathic pain [9-11]. Hara et al. have confirmed that intraperitoneal injection of paclitaxel could increase the TRPV1 level in rat plantar skin and sensitize the TRPV1 channel, which is regarded as the cause of heat hyperalgesia [7]. Some studies have shown that intraperitoneal injection of TRPV1 antagonists (such as capsazepine and SB366791) in PIPN rats would attenuate paclitaxel-induced thermal hyperalgesia in a dose-dependent manner but did not exhibit a pronounced effect on mechanical allodynia [6], further confirming the relationship between TRPV1 and PIPN thermal hyperalgesia. The activation of TRPV1 leads to depolarization of neurons and causes the production and release of neuropeptides such as CGRP and SP in peripheral and central nerve endings. Neuropeptides activate their corresponding receptors and enhance the sensitivity of nociceptors [12].

Many signaling pathways are involved in the pathological process of TRPV1 activation in the PIPN process. PKC and mitogen-activated protein kinase (MAPK) signaling cascades are considered essential in regulating TRPV1. TRP channels are often considered to be downstream of PKC signaling and linked with paclitaxelinduced pain behavior. Paclitaxel has a lipopolysaccharide (LPS)-like effect, which increases intracellular $\mathrm{Ca}^{2+}$ levels in DRG and promotes phosphorylation of PKC. Increased PKC activity in DRG was observed in PINP mouse models, and inhibition of PKC attenuated paclitaxel-induced peripheral neuropathy [13]. Studies have shown that paclitaxel could activate proteinase-activated receptors 2 (PAR2) through the PLC-PKC pathway and lead to TRPV1, TRPV4, and TRPA1 sensitivity, and eventually produce allodynia and hyperalgesia. In a variety of PKC subtypes, the importance of PKC $\varepsilon$ activation has been proved in paclitaxel-induced mechanical pain. However, PKC $\varepsilon$ v1-2 (PKC $\varepsilon$ inhibitor) has only a modest effect on reducing hyperalgesia [14].

MAPK is widely reported as the downstream of the PKC signal and its regulatory effect on TRPV1 has been studied [15]. MAPK family is a class of highly conserved serine/threonine protein kinases, while MAPK is mediated by $\mathrm{p} 38$ rather than ERK in the pathogenesis of pain [16]. p38 MAPK, as a tyrosine phosphoprotein kinase, is activated by stress signals and inflammatory stimuli and contributes to cellular responses associated with neuropathic pain $[17,18]$. Activation of p38 MAPK in DRG can increase translation and transport of TRPV1 to the terminal of the peripheral nociceptor, contributing to the maintenance of thermal hyperalgesia [16]. In general, p38 MAPK plays a crucial role in dorsal root ganglion neurons and spinal cord neurons and participates in the pathogenesis of PIPN [19]. The expression of ERK1/2 and p38 MAPK was increased in DRG tissues, and administration of SB203580 (p38 MAPK inhibitor) prevented but could not reverse paclitaxel-induced pain behavior in PIPN rat models [20]. The effect of p38 MAPK activation was limited to hyperalgesia and had no effect on mechanical hypersensitivity, which is consistent with the critical role of TRPV1 as a p38 MAPK downstream target [21].

Corydalis saxicola Bunting, affiliated with the Papaveraceae Juss., is the natural grass of the perennial herb. Given the function of clearing away heat, detoxifying dampness, relieving pain, and stopping bleeding, Corydalis saxicola Bunting has been widely applied in hepatic diseases such as hepatitis, liver cirrhosis, and liver cancer in the clinic [22]. Corydalis saxicola Bunting consists of a variety of protoberberine type I alkaloids, including dehydrocavidine, berberine, tetrahydropalmatine, $( \pm)$ cavidine, $( \pm)$ tetrahydropalmatine, and protopine, which are called Corydalis saxicola Bunting total alkaloids (CSBTA) [23, 24]. Subcutaneous injection of $50 \mathrm{mg} / \mathrm{kg}$ CSBTA tended to restore the writhing response in mice and had a significant inhibitory effect when the dose reaches $100 \mathrm{mg} / \mathrm{kg}$. $100 \mathrm{mg} / \mathrm{kg}$ CSBTA also increased the threshold for thermal stimulation in the tail-flick test [25]. Our group has previously found that oral administration of CSBTA ( $30 \mathrm{mg} / \mathrm{kg}, 60 \mathrm{mg} / \mathrm{kg}$, and $120 \mathrm{mg} / \mathrm{kg}$ ) relieved cisplatin-induced neuropathic pain by decreasing the phosphorylation p38 MAPK and downstream TRPV1 [25]. CSBTA also suppressed RANKL-induced NF- $\mathrm{kB}$ and c-Fos/NFATc1 pathways to attenuate Walker 256-induced bone pain [26]. However, there is no report 
on the therapeutic function or molecular targets of CSBTA in PIPN. Based on current studies, it is assumed that the $\mathrm{PKC} \varepsilon / \mathrm{p} 38$ MAPK/TRPV1 signaling pathway may participate in the pathological process. Therefore, the purpose of this study was to observe the therapeutic effect of CSBTA on PIPN and explore its mechanism by animal and cell experiments.

\section{Materials and methods Reagents}

The commercial paclitaxel injections (Paclitaxel Injection ${ }^{\circledR}$, Lot: H99404910) were purchased from SichuanTai Ji Group Co., Ltd (Chengdu, China). CSBTA (Yanhuanglian total alkaloids capsules, Lot: 160701) was kindly supplied by Nanjing Zhongshan Pharm Co., Ltd (Nanjing, China). Sodium carboxymethyl cellulose (CMC-Na) was purchased from Sinopharm Chemical Reagent Co., Ltd (Shanghai, China). CSBTA powder was suspended in CMC-Na solution in advance. The quality specification of the CSBTA capsule is controlled by the content of total alkaloids (calculated by dehydrocavidine) and the amount of dehydrocavidine, palmatine, and berberine. Referring to the standard sample of dehydrocavidine, palmatine, and berberine (supplied by National Institutes for Food and Drug Control, Beijing, China), the total alkaloids fraction was analyzed as $58 \%$ by HPLC-UV analysis.

\section{Animals}

Adult male Sprague-Dawley rats $(180 \pm 20 \mathrm{~g})$ were supplied by the Laboratory Animal Center of Nanjing Qinglongshan (Agreement Number: SCXK-zhe-2014-0001). All rats were maintained under the standard conditions in China Pharmaceutical University Laboratory Animal Center under the $12 \mathrm{~h}$ dark-light cycles in the humanized environment (temperature, $23 \pm 2{ }^{\circ} \mathrm{C}$, and humidity, $50 \pm 10 \%)$ with regular chow diet and tap water ad libitum. After acclimation for a week, the rats were used for the following experiments.

\section{Grouping and administration}

Rats were randomly divided into 4 groups: blank group (physiological saline \& $0.5 \% \mathrm{CMC}-\mathrm{Na}$ solution), paclitaxel group (2 mg/kg paclitaxel \& $0.5 \%$ CMC-Na solution), $30 \mathrm{mg} / \mathrm{kg}$ CSBTA group (2 $\mathrm{mg} / \mathrm{kg}$ paclitaxel \& $30 \mathrm{mg} / \mathrm{kg}$ CSBTA suspended in CMC-Na solution) and $120 \mathrm{mg} / \mathrm{kg}$ CSBTA group (2 mg/kg paclitaxel \& $120 \mathrm{mg} /$ kg CSBTA suspended in CMC-Na solution). Except for the blank group, rats were intraperitoneally injected with $2 \mathrm{mg} / \mathrm{kg}$ paclitaxel (Paclitaxel Injection ${ }^{\circledR}$, Tai Ji, Chengdu, China) at 1st, 3rd, 5th, 7th days, and the blank group was intraperitoneally given the corresponding volume of physiological saline [27-29]. From the first day of the experiment, oral administration of CSBTA with different concentrations $(30,120 \mathrm{mg} / \mathrm{kg}$ ) was given [25]. At the same time, the blank group and the model group were administered with a corresponding volume of $0.5 \%$ CMC-Na solution. During the experimental period, the body weights were recorded every day before drug administration to evaluate the potential effect of CSBTA on body weight changes.

Ahead of the final experiments, the food was deprived overnight (free access to water). After mice were anesthetized, blood was collected from the abdominal aorta, centrifuged at $3000 \mathrm{rpm}$ for $10 \mathrm{~min}$ to be harvested plasma to determine PGE2, TNF- $\alpha$, and IL-1 $\beta$. L4-L6 segment spinal cord, DRG, and plantar skin were harvested and immediately stored at $-80^{\circ} \mathrm{C}$ till analysis.

\section{Mechanical hyperalgesia-Von-Frey test}

The mechanical pain threshold of rats was detected by Von-Frey filament according to the "up and down" method initiated by Chaplan [30]. As described previously [25], the rats were individually placed in a transparent plexiglass box with a cover at the top and a reticular structure at the bottom. Every rat was subjected to an adaptive test 1 week before the formal experiment. After adaptation for $15 \mathrm{~min}$, the mechanical pain threshold was measured when rats were in a peaceful state, and the movement of walking and scratching disappeared. VonFrey filament (Stoelting Company, Chicago, USA, stimulus intensity range: $4-180 \mathrm{~g}$ ) was used to prick the middle area of the ipsilateral posterior toe through the bottom mesh. The fiber needle vertically pressed the plantar skin until it was warped into a " $\mathrm{C}$ " shape. If the hind paw's retraction, movement, or lameness appeared, a positive reaction " $\mathrm{X}$ " was designated and recorded the corresponding value. And then, the strength nearest to lowintensity was used to stimulate, and negative reaction "O" was recorded if there were no response after stimulus for more than $5 \mathrm{~s}$. Sequentially, a closest higher intensity was continued to stimulate till the rats showed positive behavior. Stimulation was conducted every $2 \mathrm{~min}$ and repeated six times. A double-blind trial tested mechanical hyperalgesia. Followingly, we could obtain the "X" and "O" sequences and finally calculated the mechanical pain threshold. The mechanical pain threshold test in each rat was repeated three times to calculate the average response.

\section{Thermal sensitivity-laser thermal pain meter}

PL-200 laser thermal pain meter (PL-200, Taimeng Technology, Chengdu, China) was used to detect heat hyperalgesia to assay the latent period of heat-stimulated retraction reflex. As described previously [25], each animal was subjected to an adaptive test 1 week before the formal experiment. Under constant ambient 
temperature, rats were placed in an observation box for $15 \mathrm{~min}$ in advance to make them accommodative and tranquil. Afterward, the optical source (intensity at 35\%) was moved to plantar, and the time (from the initial irradiation) was recorded when thermal pain reaction (contracting claw, licking foot, and scratching) occurred. The cutoff time was $25 \mathrm{~s}$ to prevent possible injury from high temperature. The thermal sensitivity test was repeated three times at least 5 min intervals in each rat, and the average was applied for data analysis. A double-blind trial tested thermal sensitivity.

\section{Thermal sensitivity - tail immersion assay}

Half an hour after drug administration, rats were subjected to a tail-flick test. As described previously [27], each animal was subjected to an adaptive test 1 week before the formal experiment. After the rat was no longer struggling, the tail was immersed into a water bath, and we recorded the time from immersion to tail flick reaction. The temperature was set at $47{ }^{\circ} \mathrm{C}$, adopted by the tail-flick time lasting $10 \mathrm{~s}$ for most rats. To prevent the injury from high temperature, we selected $20 \mathrm{~s}$ as a cutoff time. Each rat was tested three times with at least 5 min intervals, and the average of the three tests was used for data analysis. A double-blind trial tested thermal sensitivity.

\section{Thermal sensitivity-cold hyperalgesia}

Similarly, rats were subjected to a cold hyperalgesia test 30 min after drug administration. As described previously [31, 32], we used dry ice to assay the cold pain threshold of rats, and the results were expressed as the first occurrence time of paw withdrawal, lameness, scratching, or other reactions in rats after cold stimulation. The room's temperature was kept stable, and rats were placed in an observation box for 15 min to make them quiet. After the dry ice placing on plantar, we recorded time from the beginning to the emergence of contracting claw, licking foot, or scratching. The cutoff time was $90 \mathrm{~s}$ to avoid skin cold injury. Each animal was subjected to an adaptive test 1 week before the formal experiment. A double-blind trial tested cold hyperalgesia.

\section{TNF- $\alpha$, IL-1 $\beta$, and PGE2 in serum and plantar skin tissues}

After $12 \mathrm{~h}$ of the 40th day, rats in each group were fasted for $10 \mathrm{~h}$ (free access to water) and anesthetized. Blood was rapidly withdrawn from the abdominal aorta to clean EP tubes. Serum was harvested after centrifugation at $3000 \mathrm{rpm}$ for $10 \mathrm{~min}$. The harvested plantar skin tissues from corresponding rats were immediately shaved on the ice. A piece of $1 \mathrm{~g}$ tissue was collected and cut into pieces. Subsequently, they were soaked in $5 \mathrm{ml}$ physiological saline after a gentle vortex at $4{ }^{\circ} \mathrm{C}$ for $2 \mathrm{~h}$. Afterward, the mixtures were centrifuged at $3000 \mathrm{rpm}$ for $10 \mathrm{~min}$ at $4{ }^{\circ} \mathrm{C}$, and the harvested supernatant was stored at $-80{ }^{\circ} \mathrm{C}$ till analysis [25]. The levels of TNF- $\alpha$, IL-1 $\beta$, and PGE2 in obtained plantar skin supernatant and serum were separately detected by ELISA (Calvin Biotechnology, Suzhou, China) according to kit instructions.

\section{Preparation and quality control of Corydalis saxicola Bunting total alkaloids}

Corydalis saxicola Bunting total alkaloids (CSBTA) were provided by Nanjing Zhongshan Pharmaceutical Co., Ltd. (Batch number: 191201). According to China Pharmacopoeia (2005 version), the composition of CSBTA was determined by high-performance liquid chromatography (Appendix VI D) [26, 33]. In brief, the quantitative analysis of CSBTA by high-performance-liquid chromatography (HPLC) was performed by SHIMADZU LC-20 AT HPLC system (SHIMADZU, Japan) equipped with a quaternary ammonium salt pump solvent management system, an online degasser, and an autosampler. The separation was conducted by an Agilent ZARBAX SB-C18 column (the USA, $4.6 \times 250 \mathrm{~mm}, 5 \mu \mathrm{m}$ ) with the $10 \mu \mathrm{l}$ injection volume, and the column temperature was maintained at $30{ }^{\circ} \mathrm{C}$. The mobile phase was composed of acetonitrile (A) and potassium dihydrogen phosphate solution (B, $0.01 \mathrm{~mol} / \mathrm{l})$, and gradient elution was set as $25 \% \mathrm{~A}: 75 \% \mathrm{~B}$ with the $1 \mathrm{ml} / \mathrm{min}$ flow rate. The detection was performed as $347 \mathrm{~nm}$. A mixed solution of dehydrocarvidine $20 \mu \mathrm{g}$, palmatine hydrochloride $20 \mu \mathrm{g}$, and berberine hydrochloride $10 \mu \mathrm{g}$ was prepared in $1 \mathrm{ml}$ methanol as a standard solution. The CSBTA test solution consists of $25 \mathrm{mg}$ CSBTA dissolved in $50 \mathrm{ml}$ methanol. The representative chromatography was depicted in Fig. 1. For the in vitro experiments, $50 \mathrm{mg}$ CSBTA powder was dissolved in $1 \mathrm{ml}$ DMSO as stock solution.

\section{Primary DRG neurons cell culture}

As described previously [34, 35], the back skin of rats was quickly cut with surgical scissors to isolate the spine after anesthesia. DRG tissue was extracted and placed in a MEM medium tube (Gibco, USA) without fetal bovine serum (FBS, Gibco, USA). Subsequently, an aliquot of $2 \mathrm{ml}$ collagenase A (Roche, USA, $1 \mathrm{mg} / \mathrm{ml}$ ) was added to digest cells for about $90 \mathrm{~min}$. Then, the digestion solution was replaced by $0.25 \%$ trypsin (Gibco, USA) for another $20 \mathrm{~min}$. Finally, the digestion was terminated by the MEM medium containing 10\% FBS. MEM medium was mechanically triturated with a $1 \mathrm{ml}$ pipette until the solution turned milky. After filtering through a $70 \mu \mathrm{m}$ cell strainer, the solution was centrifuged at $1000 \mathrm{rpm}$ for $5 \mathrm{~min}$. The dissociated neurons suspended in MEM medium containing 10\% FBS and $1 \%$ penicillin and streptomycin mixture (Gibco) were 


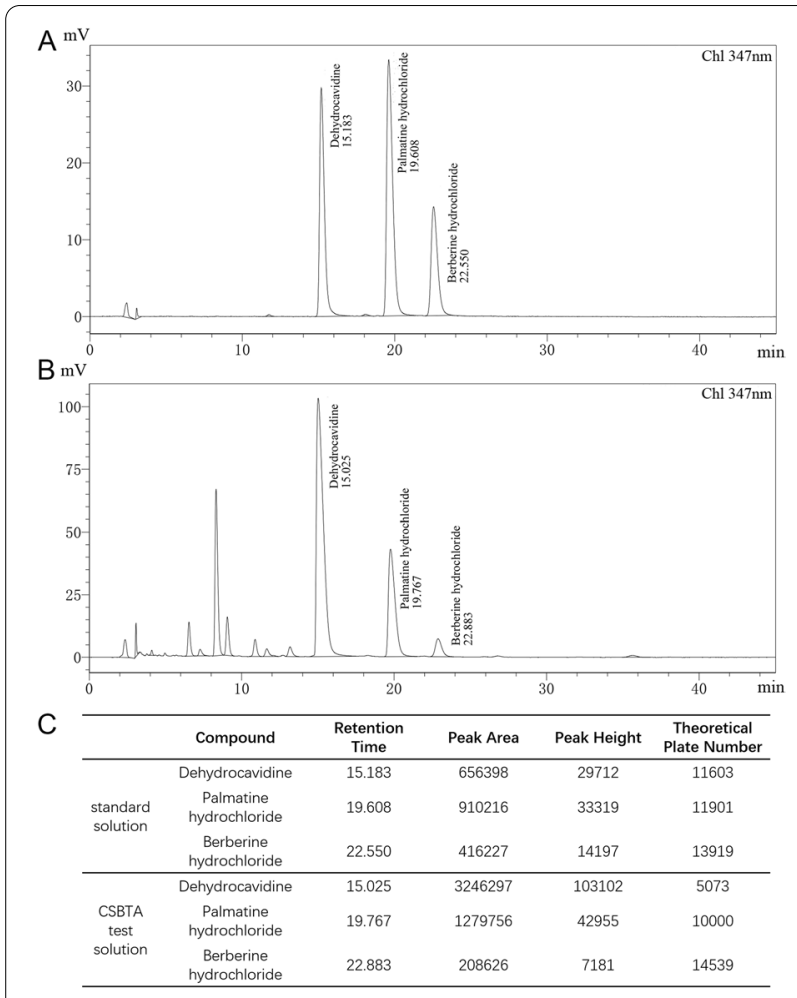

Fig. 1 HPLC chromatograms of CSBTA. A HPLC chromatograms of the standard solution was detected at $347 \mathrm{~nm}$. The retention time of dehydrocarvidine, palmatine hydrochloride, and berberine hydrochloride were $15 \mathrm{~min}, 19.6 \mathrm{~min}$, and $22.5 \mathrm{~min}$, respectively. B HPLC chromatograms of CSBTA test solution detected at $347 \mathrm{~nm}$. C HPLC chromatograms information of standard solution and CSBTA test solution detected at $347 \mathrm{~nm}$. The contents of dehydrocarvidine, palmatine hydrochloride, and berberine hydrochloride in CSBTA were $19.8 \%, 5.6 \%$, and $1 \%$, respectively

plated onto poly-L-lysine-coated 6-well plates (Corning Life Sciences, Acton, MA) at a density of $4 \times 10^{5}$ cells/ well and incubated at $37{ }^{\circ} \mathrm{C}$ in a $5 \% \mathrm{CO} 2$ and $95 \%$ humidity atmosphere. After culturing for $24 \mathrm{~h}$, MEM medium was replaced with neuronal growth medium (Neurobasal medium: B27 $=50: 1$, both purchased from Gibco, USA), and $1 \%$ other agents including penicillin and streptomycin mixture (Gibco), L-Glutamine $(0.1 \mathrm{mg} / \mathrm{ml}$, SigmaAldrich), and cytarabine (5 $\mu \mathrm{g} / \mathrm{ml}$, Sigma Aldrich) was added. Medium with supplements was changed every two days. The cells were used for experiments on the 4th10th days.

\section{Cell viability assay}

CSBTA group was treated with $0,0.05,0.5,5,50 \mu \mathrm{g} / \mathrm{ml}$ of CSBTA, and paclitaxel groups were given $0,1,10$, 100, 500, $1000 \mathrm{nM}$ paclitaxel (A4393, APExBIO, USA) on the 4th day of primary DRG neurons. Five days after administration, a Cell Counting Kit-8 (CCK-8) solution
(Dojindo, Japan) was added. After incubation for $4 \mathrm{~h}$, absorbance at $450 \mathrm{~nm}$ was measured with a microplate reader.

\section{Drug treatment}

Primary DRG neuron cells were divided into the following five groups for the experiment on the 4th day: blank group (phosphate buffer saline), paclitaxel group (300 nM paclitaxel), $25 \mu \mathrm{g} / \mathrm{ml}$ CSBTA group (300 nM paclitaxel $+25 \mu \mathrm{g} / \mathrm{ml}$ CSBTA), $50 \mu \mathrm{g} / \mathrm{ml}$ CSBTA group $(300 \mathrm{nM}+50 \mu \mathrm{g} / \mathrm{ml} \mathrm{CSBTA})$ and PKC $\varepsilon$ inhibitor group (300 nM paclitaxel+100 nM Staurosporine (A8192, APExBIO, USA)). Staurosporine group was regarded as positive control. In some trials, $1 \mu \mathrm{M}$ SB203580 (HY10256, MCE) was administered as an inhibitor of p38 MAPK. Five days after administration, cells were collected for subsequent experiments.

\section{Western blot analysis}

As described previously [25], the spinal cord and DRG were lysed in lysis buffer (RIPA: PMSF: phosphatase inhibitor $=100: 1: 1)$ at 1:5 $\left(\mathrm{mg} \cdot \mu 1^{-1}\right)$ and vigorously crushed by glass homogenizer on ice. An appropriate aliquot of lysis buffer was added, and cell scrapers on ice cells scrapped cells. The homogenates were immediately centrifuged at $12,000 \mathrm{rpm}$ for $20 \mathrm{~min}$ at $4{ }^{\circ} \mathrm{C}$. Protein quantification was performed according to the Bicinchoninic Acid Protein Assay kit (Nanjing Jiancheng Bioengineering Institute, Nanjing, China). Subsequently, extracted protein samples $(6 \times$ loading buffer: supernatant $=1: 2, \mathrm{v} / \mathrm{v}$ ) were boiled for $15 \mathrm{~min}$ and stored at $-80{ }^{\circ} \mathrm{C}$ till analysis.

Loading protein $(50 \mu \mathrm{g})$ was electrophoresed and separated on a $10 \%$ SDS-polyacrylamide gel (SDS-PAGE) and transferred to a polyvinylidene difluoride (PVDF) membrane $(0.22 \mu \mathrm{m}$, Pall, USA). PVDF membrane was blocked in 5\% skimmed milk in TBST buffer (Tris- $\mathrm{HCl}$, $5 \mathrm{mM}, \mathrm{pH}$ 7.6, $\mathrm{NaCl} 136 \mathrm{mM}, 0.05 \%$ Tween-20) at room temperature for $2 \mathrm{~h}$, followed by incubation with different primary antibodies- $\beta$-actin (1:5000, Bioworld, USA), p38 (1:1000, Abcam, USA), p-p38 (1:1000, Cell Signaling Technology, USA), PKCe (1:1000, Abcam, USA) and TRPV1 (1:200, Alomone, Israel) in TBST at 4 ${ }^{\circ} \mathrm{C}$ overnight. After being washed with TBST three times, membranes were further incubated with horseradish peroxides (HRP)-conjugated secondary antibody (1:5000 dilution in TBST) for $2 \mathrm{~h}$ at room temperature. Antibody binding was detected by enhanced chemiluminescence (ECL). The $\beta$-actin was used as an endogenous reference. Imagines were acquired by Bio-Rad and quantified by densitometry analysis using Image J software. 


\section{Real-time qPCR analysis}

Spinal cord and DRG tissue weighing $100 \mathrm{mg}$ were homogenized in $1 \mathrm{ml}$ Trizol reagent (Invitrogen, USA) on ice to extract total RNA. Cells were lysed with $1 \mathrm{ml}$ Trizol reagent per well to extract total RNA [36]. RT-PCR was proceeded according to HieffTM First Strand cDNA Synthesis SuperMix Kit instruction. The $\beta$-actin was used as an endogenous reference. Quantitative PCR was performed in $20 \mu$ reactions using HieffTM qPCR SYBR Green Mester Mix (No Rox) kit. Primer sequences are listed in Table 1 . The ratios between the candidate genes and $\beta$-actin mRNA were detected by BioRad image system (Bio-Rad, USA) and calculated by the comparative threshold cycle $(\mathrm{Ct})$ method.

\section{Immunofluorescence staining}

After paclitaxel and CSBTA treatment, primary DRG neurons were fixed with $4 \%$ paraformaldehyde and then blocked with 5\% BSA for $1.5 \mathrm{~h}$. After incubation with primary antibody (anti-PKC $\varepsilon, 1: 100$ ) overnight at $4{ }^{\circ} \mathrm{C}$, cells were incubated with fluorescein isothiocyanate-conjugated secondary antibody for $2 \mathrm{~h}$ at $37{ }^{\circ} \mathrm{C}$. Nuclei were stained with DAPI (Beyotime Institute of Biotechnology, Shanghai, China). The immunofluorescence images were visualized under a confocal scanning microscope (Zeiss LSM 700, Jena, Germany).

\section{Statistical analysis}

Data were expressed as a mean \pm SD (standard deviation) of at least three independent experiments. Statistical analysis was performed using GraphPad Prism software, version 6.0 (San Diego, CA, USA). The statistical significance was analyzed using unpaired Student's t-test, or one-way ANOVA followed by Dunnett's multiple comparison test. A value of $\mathrm{p}<0.05$ was considered to be statistically significant.

\section{Results}

The purity of dehydrocarvidine, palmatine hydrochloride, and berberine hydrochloride in CSBTA

As shown in Fig. 1, the retention time of dehydrocarvidine, palmatine hydrochloride, and berberine hydrochloride were about $15 \mathrm{~min}, 19.6 \mathrm{~min}$, and $22.5 \mathrm{~min}$, respectively. The CSBTA sample had no abnormal peak at the appropriate location. The results showed that the contents of dehydrocarvidine, palmatine hydrochloride, and berberine hydrochloride in CSBTA were $19.8 \%, 5.6 \%$, and $1 \%$, respectively.

\section{CSBTA normalized the neurological behaviors in PIPN rats}

In this experiment, paclitaxel caused obvious mechanical, cold and thermal allodynia and hyperalgesia in rats (Fig. 2a), implying peripheral neuropathy in rats. During this experiment period, there was no death occurred. The body weight of rats showed an increasing trend and did not exhibit significant differences among groups (Fig. $2 \mathrm{~b}$, $\mathrm{p}>0.05)$.

Compared with the paclitaxel group, $30 \mathrm{mg} / \mathrm{kg}$ and $120 \mathrm{mg} / \mathrm{kg}$ CSBTA group gradually recovered mechanical threshold from the 20th and the 16th day (Fig. 2c, ** $\mathrm{p}<0.01)$. There was no significant difference in mechanical threshold between the $120 \mathrm{mg} / \mathrm{kg}$ CSBTA group and the blank group after the 24th day by Von-Frey test (Fig. 2c, p>0.05). $30 \mathrm{mg} / \mathrm{kg}$ or $120 \mathrm{mg} / \mathrm{kg}$ CSBTA groups gradually improved cold pain threshold from the 20th and the 18th day (Fig. $2 \mathrm{~d}$, ${ }^{* * *} \mathrm{p}<0.01$ ), and there was no significant difference between $120 \mathrm{mg} / \mathrm{kg}$ CSBTA group and blank group after 20 days (Fig. 2d, p >0.05).

The response to thermal sensitivity was measured by laser thermal pain meter and tail immersion assay. Compared with the thermal sensitivity in the paclitaxel group (Fig. 2e), $30 \mathrm{mg} / \mathrm{kg}$ or $120 \mathrm{mg} / \mathrm{kg}$ CSBTA recovered the thermal threshold from the 16th day $(* * \mathrm{p}<0.01)$ in the laser thermal pain experiment. In comparison, the $30 \mathrm{mg} / \mathrm{kg}$ and $120 \mathrm{mg} / \mathrm{kg}$ CSBTA group exhibited no distinct difference compared with the blank group $(p>0.05)$ from the 24th and the 22nd day. In the tail

Table 1 The primers for the quantitative RT-PCR

\begin{tabular}{lll}
\hline Gene & Forward primer & Reverse primer \\
\hline TRPV1 & AGAAGGGGACCAGGGCAAAG & TCAACGAGGACCCAGGCAACT \\
PKC epsilon & TCTGGAGCAGCAATAGAGTT & TCATCAAGGTGTTAGGAAAG \\
Tac1 & CTCACAAAGGCATAAAACAGATT & TGAATAGATAGTGCGTTACAGGGTT \\
CGRP & GTCCCTCCTCTCCTTTCCAGTT & AGATTCCAGATACCATCCTTTGCC \\
PGE2 & AGGGAGCATACAGCGAGGTG & TGCGGATTGTCTGGCAGTAGC \\
TNF-a & GCGTGTTCATCCGTTCTCTACC & TACTTCAGCGTCTCGTGTGTTCT \\
\hline -actin & ATCATTGCTCCTCCTGAGCG & CGCAGCTCAGTAACAGTCCG \\
\hline
\end{tabular}




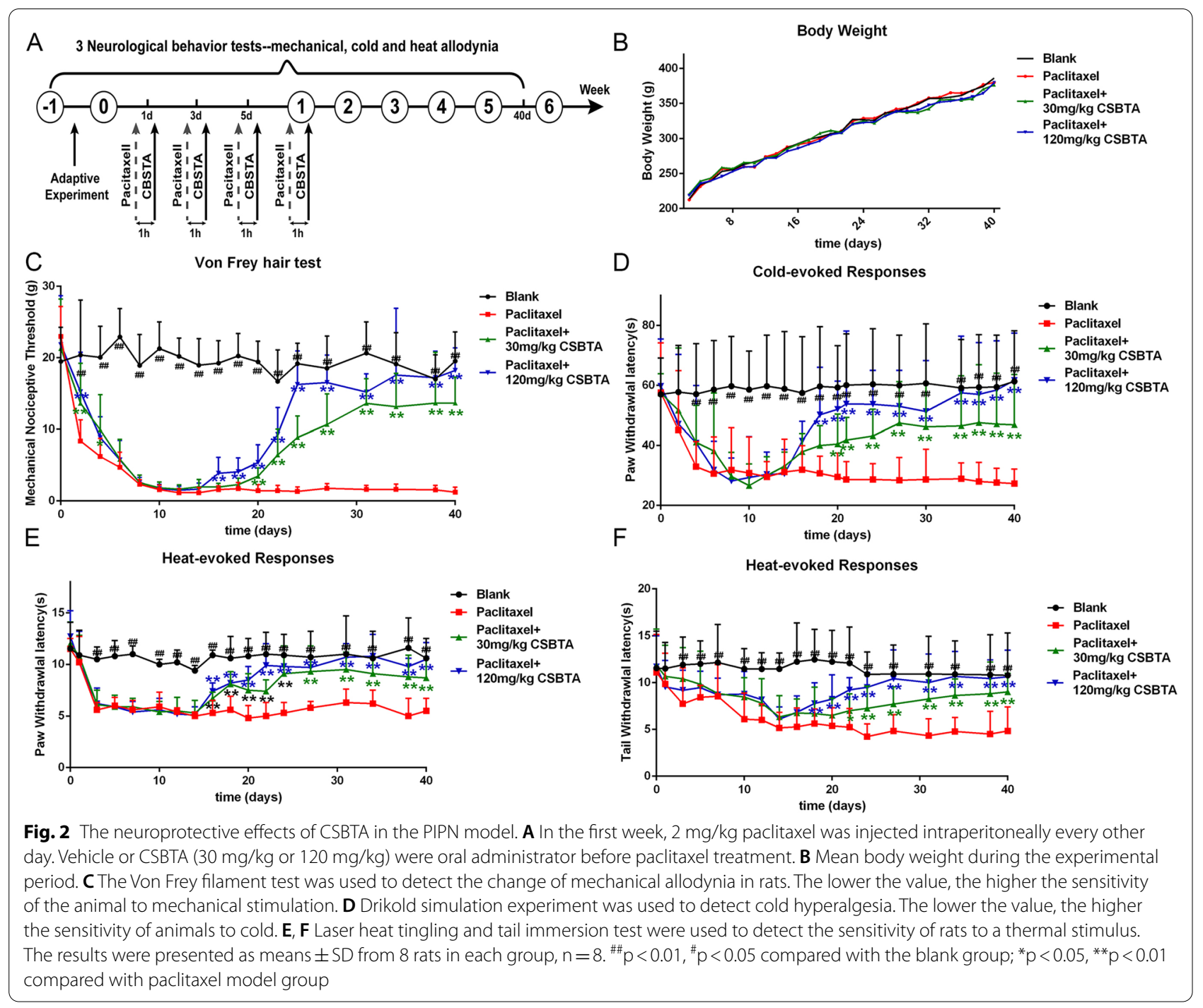

immersion experiment (Fig. 2f), $30 \mathrm{mg} / \mathrm{kg}$ and $120 \mathrm{mg} /$ $\mathrm{kg}$ CSBTA restored thermal sensitivity from the 22nd and the 18th day (**"p $<0.01)$. Compared with the blank group, the $120 \mathrm{mg} / \mathrm{kg}$ CSBTA group already had no significant difference after the 24th day $(\mathrm{p}>0.05)$. On the 40th day, $120 \mathrm{mg} / \mathrm{kg}$ CSBTA group and $30 \mathrm{mg} / \mathrm{kg}$ CSBTA group had a significant difference in mechanical pain thresholds $(\mathrm{P}<0.01)$, but there were no significant differences in thermal sensitivity thresholds $(\mathrm{P}>0.05)$. All these results indicated that CSBTA made neurological behaviors of PIPN gradually recover to normal.

\section{CSBTA decreased the levels of IL-1 $\beta$, TNF- $\alpha$, PGE2, and neuropeptides in PIPN rats}

The inflammatory process is considered a potential trigger for chemotherapy-induced peripheral neuropathy. The release of pro-inflammatory cytokines or chemokines is regarded as the major mechanism of neuro-immune response [2, 37]. We measured the levels of inflammatory factors IL-1 $\beta$, TNF- $\alpha$, and PGE2 in serum and plantar skin supernatant. As shown in Fig. 3a and $b$, cytokines were significantly increased in the paclitaxel group compared with the blank group (\#\#p $<0.01)$. However, CSBTA $(30 \mathrm{mg} / \mathrm{kg})$ reduced cytokines to some extent ("p<0.05), while CSBTA $(120 \mathrm{mg} / \mathrm{kg})$ presented more obvious improvements $\left({ }^{* *} \mathrm{p}<0.01\right)$, especially in the contents of serum IL- $1 \beta$ and plantar skin supernatant TNF- $\alpha$.

SP and CGRP are excitatory neuropeptides released by the primary sensory afferent nerve in the dorsal horn [38]. Several studies have reported that SP and CGRP released from the spinal cord and DRG were involved in PIPN [39]. The results indicated that paclitaxel significantly increased the levels of inflammatory factors (PGE2, TNF- $\alpha$ ) and neuropeptides (CGRP and SP, SP is synthesized by tachykinin, TAC-1) in the spinal cord 


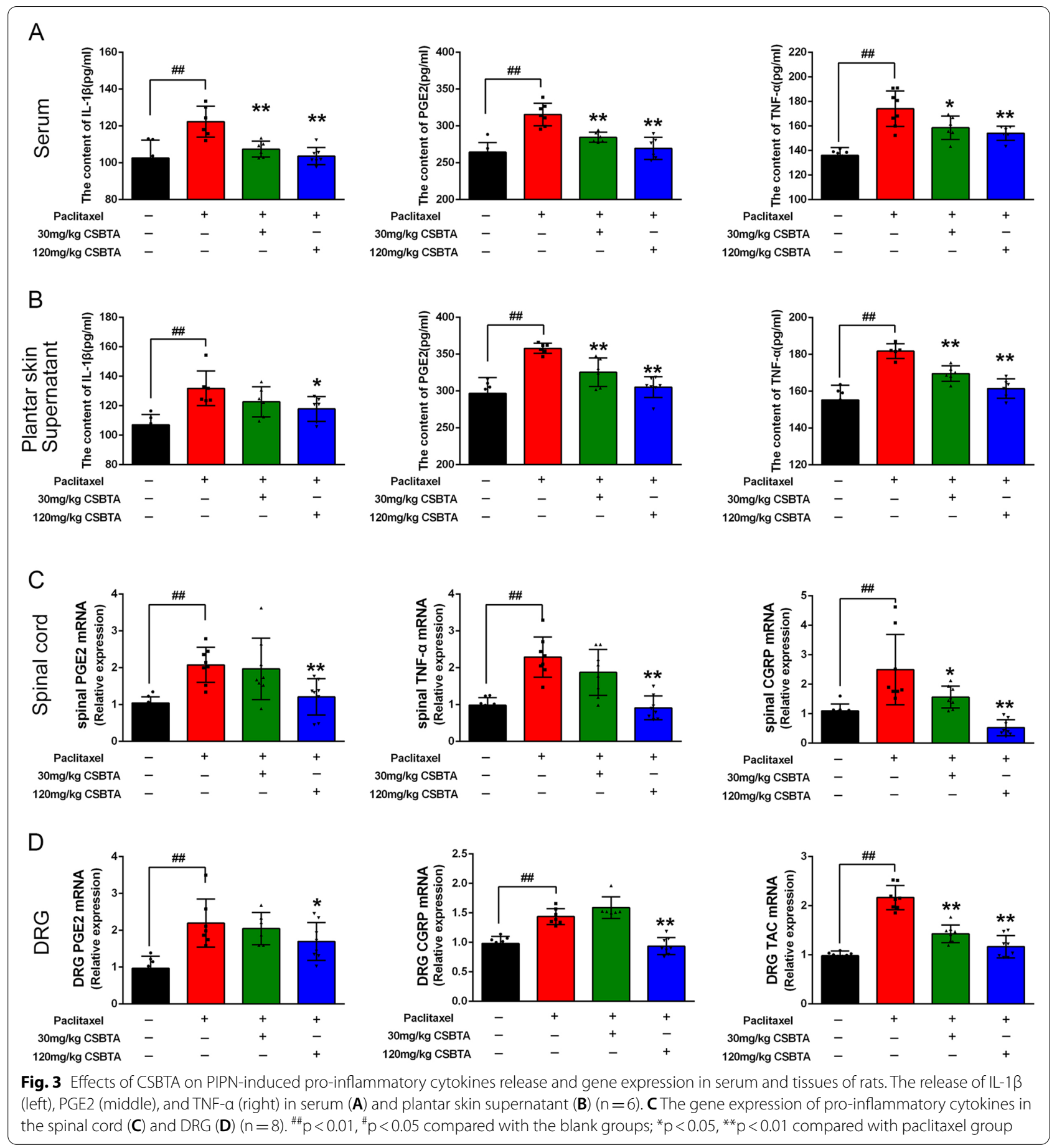

and DRG compared with the blank group (Fig. 3c and d, $\# \mathrm{p}<0.05$ or \#\# $\mathrm{p}<0.01$ ), while $120 \mathrm{mg} / \mathrm{kg}$ CSBTA group exerted an inhibitory effect on the mRNA levels of those factors ("p $<0.05$ or *" $\mathrm{p}<0.01$ ). Compared with $30 \mathrm{mg} / \mathrm{kg}$ CSBTA, $120 \mathrm{mg} / \mathrm{kg}$ CSBTA has a better inhibitory effect on cytokines, such as CGRP and TNF- $\alpha$ in the spinal cord, and PGE2 in DRG.
CSBTA inhibited PKCE/p38 MAPK/TRPV1 pathway in the spinal cord and DRG

Western-blot and RT-qPCR analyzed the protein and mRNA expressions of PKCe, TRPV1, p-p38 MAPK from the spinal cord and DRG. CSBTA could significantly inhibit protein levels of PKCe, p-p38 MAPK, TRPV1 (Fig. $4,{ }^{*} \mathrm{p}<0.05$ or ${ }^{* *} \mathrm{p}<0.01$ ). Compared with $30 \mathrm{mg} /$ 


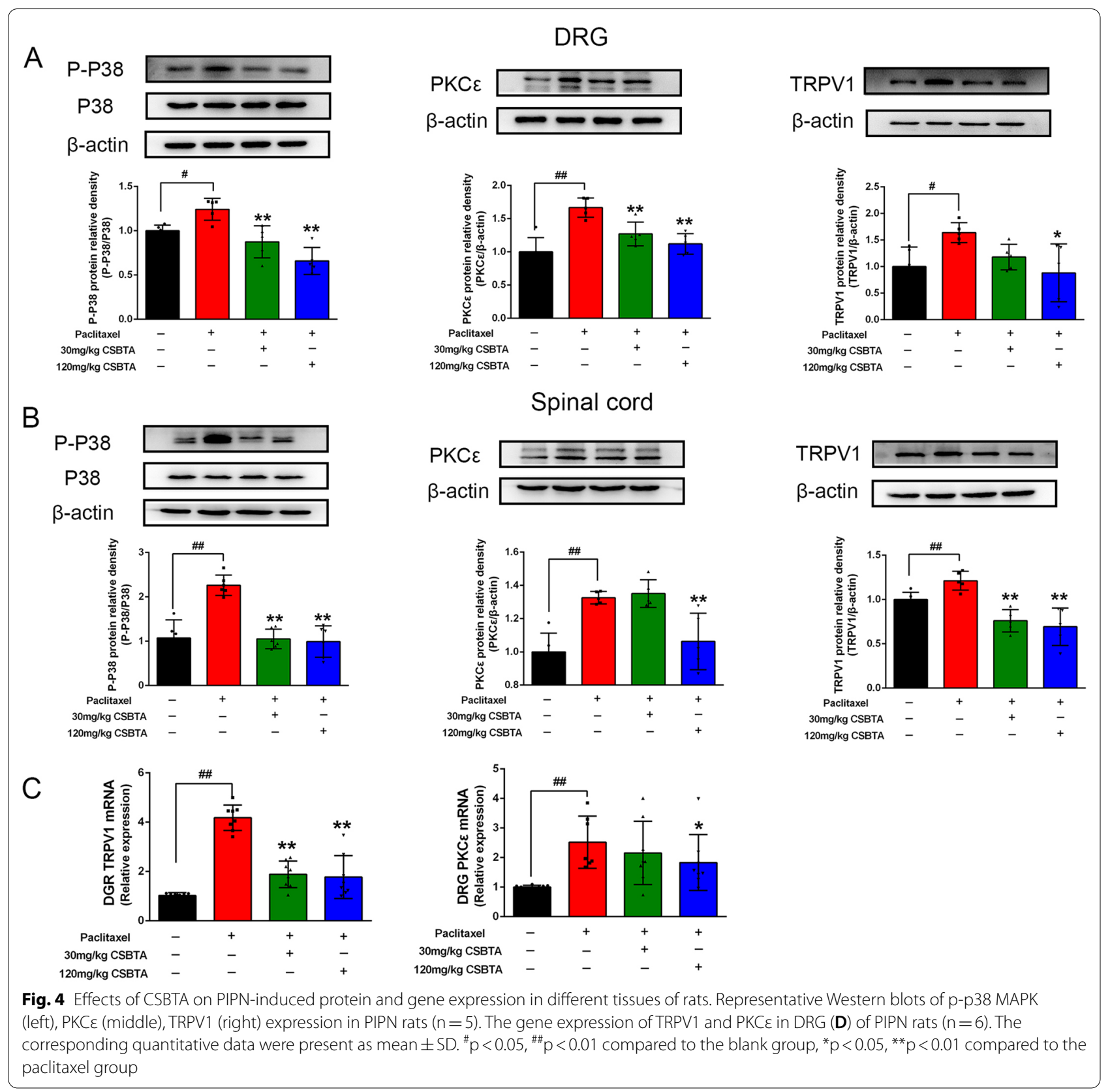

$\mathrm{kg}, 120 \mathrm{mg} / \mathrm{kg}$ CSBTA had more significant inhibition on $\mathrm{PKC} \varepsilon$ in the spinal cord $(\mathrm{P}<0.05)$. There is no significant difference in the DRG between $30 \mathrm{mg} / \mathrm{kg}$ and $120 \mathrm{mg} /$ $\mathrm{kg}$ CSBTA groups $(\mathrm{P}>0.05)$. The mRNA levels of TRPV1 and $\mathrm{PKC} \varepsilon$ were increased in DRG tissues of the paclitaxel group, whereas $120 \mathrm{mg} / \mathrm{kg}$ CSBTA significantly inhibited the expression of these genes.

According to the above results, the preliminary assumption was that CSBTA reduced the levels of proinflammatory cytokines (such as IL-1 $\beta$, TNF- $\alpha$, PGE2) and alleviated the symptoms of chronic neuropathic pain via regulating $\mathrm{PKC} / \mathrm{p} 38 \mathrm{MAPK} / \mathrm{TRPV} 1$ pathway in PIPN rats. In order to confirm the mechanism of CSBTA on the amelioration of PIPN, we conducted the following experiments in vitro.

\section{CSBTA reduced the PGE2, TNF- $a$, and CGRP mRNA levels in paclitaxel-stimulated primary DRG neurons}

Primary DRG neurons were incubated with a series of CSBTA and paclitaxel concentrations for 5 days, and 

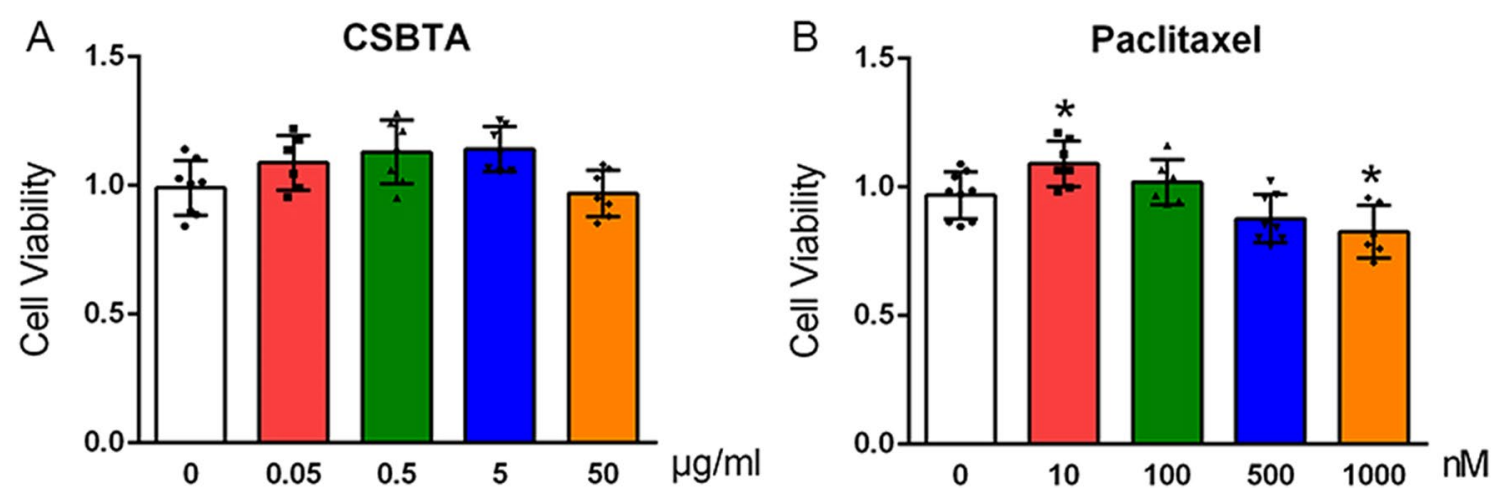

Fig. 5 Effects of CSBTA and paclitaxel on primary DRG neurons viability. At 4th days, CSBTA $(0,0.05,0.5,5,50 \mu \mathrm{g} / \mathrm{ml})$ and paclitaxel $(0,10,100,500$, $1000 \mathrm{nM}$ ) were administered for 5 days, respectively. The absorbance value at $450 \mathrm{~nm}$ was measured. The data were presented as means $\pm S D, n=6$. $\# \mathrm{p}<0.01, \# p<0.05$ compared with the blank group; ${ }^{*} p<0.05,{ }^{* *} p<0.01$ compared with paclitaxel group

the CCK-8 measured cell viability. As shown in Fig. 5, $300 \mathrm{nM}$ paclitaxel and $50 \mu \mathrm{g} / \mathrm{ml}$ CSBTA did not significantly affect cell viability $(\mathrm{p}>0.05)$, which are suitable concentration in vitro experiments.
Paclitaxel up-regulated the expression of PGE2, TNF- $\alpha$, and CGRP in primary DRG neurons (Fig. 6, $\# \#<<0.01)$. These cytokines could be inhibited by $25 \mu \mathrm{g} / \mathrm{ml} \mathrm{CSBTA}, 50 \mu \mathrm{g} / \mathrm{ml} \mathrm{CSBTA}$, and $100 \mathrm{nM}$
A

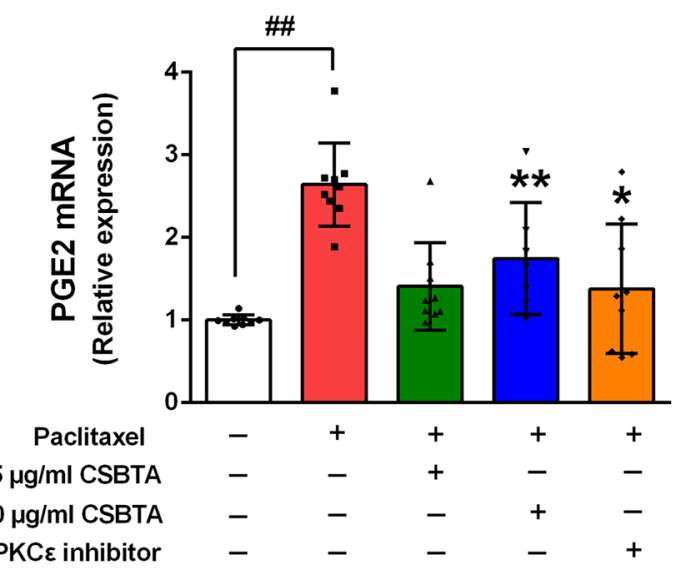

B

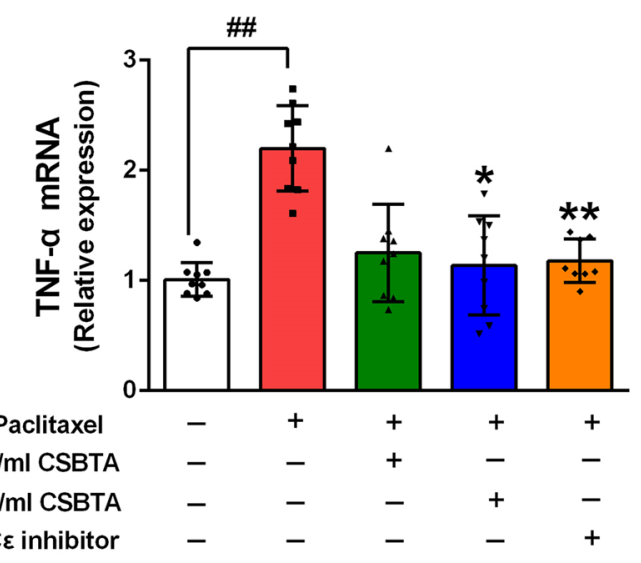

C

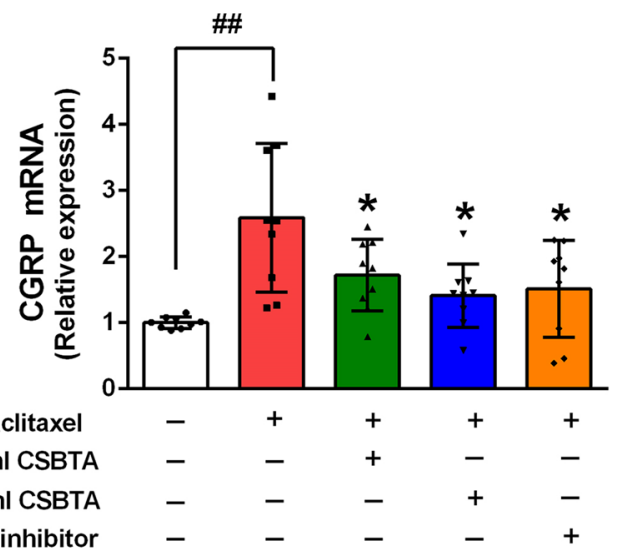

Fig. 6 Effects of CSBTA on PGE2 (A), TNF-a (B), and CGRP (C) mRNA levels in paclitaxel-stimulated primary DRG neurons. The data were presented as means $\pm S D, n=9 .{ }^{\#} p<0.01,{ }^{\#} p<0.05$ compared with the blank group; ${ }^{*} p<0.05$, ${ }^{*} p<0.01$ compared with paclitaxel group 
staurosporine. $50 \mu \mathrm{g} / \mathrm{ml} \mathrm{CSBTA} \mathrm{significantly} \mathrm{repressed}$ the gene expressions of PGE2, TNF- $\alpha$, and CGRP compared with those in the paclitaxel group (*p $<0.05$ or **" $\mathrm{p}<0.01)$.
CSBTA regulated the PKCE/p38 MAPK/TRPV1 pathway in paclitaxel-stimulated primary DRG neurons

In Fig. 7, the paclitaxel group significantly increased the expressions of PKCe (a), p-p38 MAPK (b) and TRPV1
A
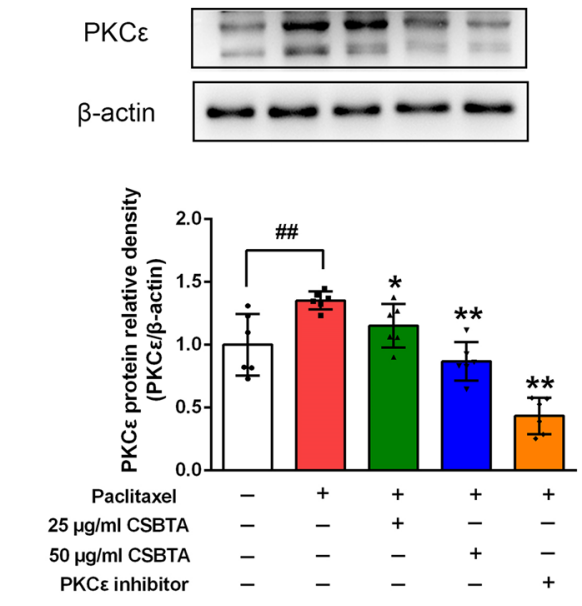

C

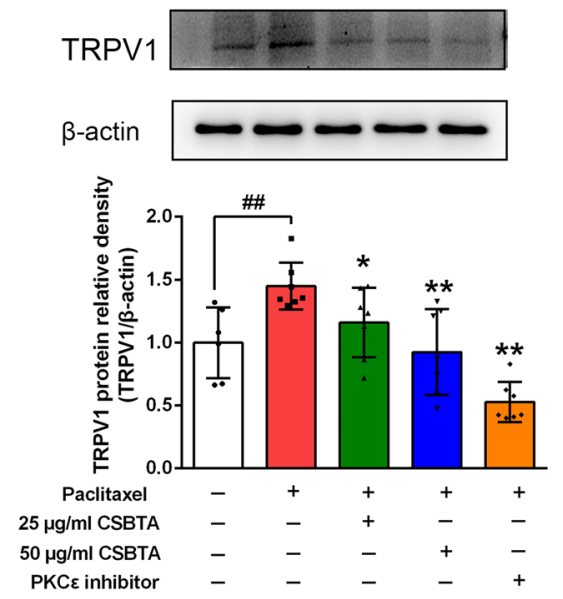

E

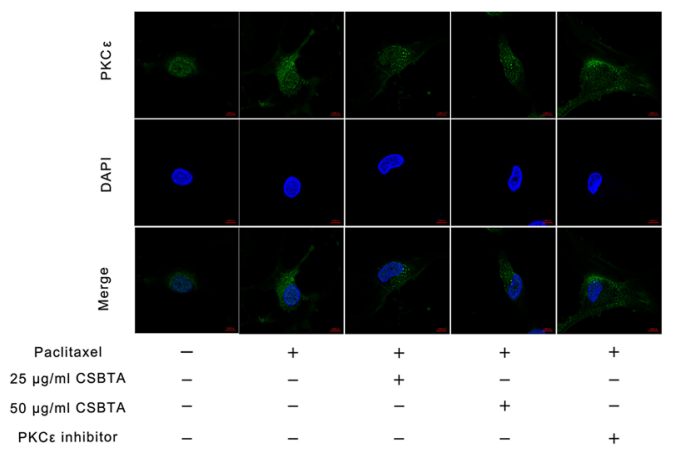

B

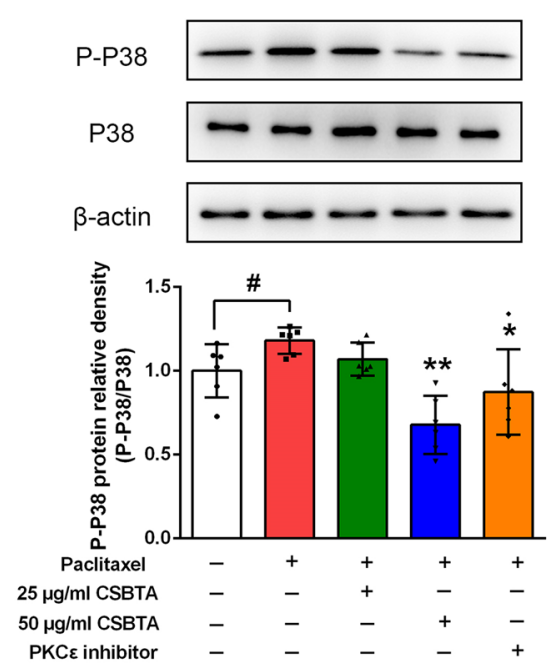

D

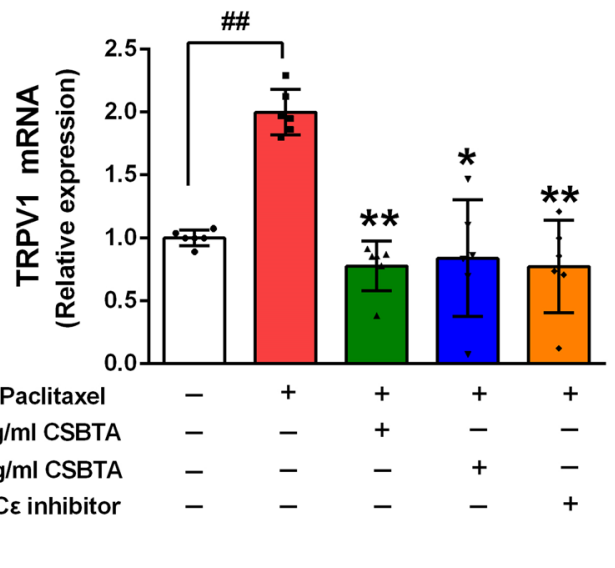

$\mathrm{F}$

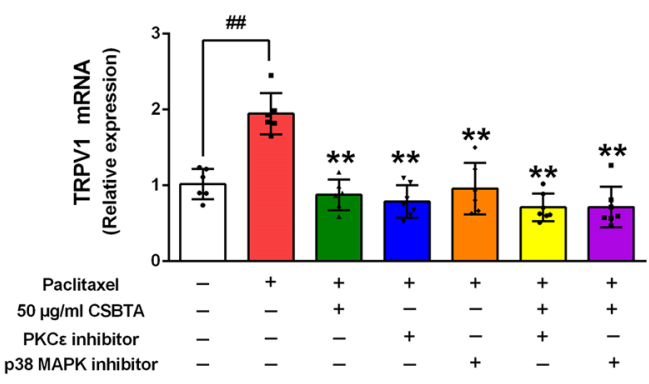

Fig. 7 Effects of CSBTA on the protein expression of PKC $\varepsilon(\mathbf{A})$, p-p38 MAPK (B), and TRPV1 (C) and the TRPV1 mRNA levels (D, F) in paclitaxel-stimulated primary DRG neurons. The corresponding quantitative data were present as mean \pm SD. $n=6$. E Representative images of PKC $\varepsilon$ (green) and DAPI (blue) stained DRG neuron. Scale bar, $5 \mu \mathrm{m} .{ }^{*} p<0.05,{ }^{\# \#} p<0.01$ compared with the blank group, ${ }^{*} p<0.05,{ }^{* *} p<0.01$ compared with the paclitaxel group 
protein (c) and TRPV1 mRNA level (d) in primary DRG neurons compared with the blank group $(\# \# \mathrm{p}<0.01)$, whereas CSBTA $(50 \mu \mathrm{g} / \mathrm{ml})$ and staurosporine $(100 \mathrm{nM})$ could significantly reduce relevant protein expressions and TRPV1 mRNA level (**p $<0.01)$. In line with the idea that CSBTA treatment decreases the PKCe expression, paclitaxel increased the fluorescence intensity of $\mathrm{PKC} \varepsilon$ in primary DRG neurons, and this effect was suppressed by $50 \mu \mathrm{g} / \mathrm{ml} \mathrm{CSBTA}$ and $100 \mathrm{nM}$ staurosporine (Fig. 7e).

As shown in Fig. 7a-e, staurosporine, as a PKCe inhibitor, not only significantly blocked the increase of PKC $\varepsilon$ protein expression induced by paclitaxel but also obviously inhibited the paclitaxel-induced p38 MAPK phosphorylation as well as the protein and mRNA levels of TRPV1. In order to further explore the relationship between PKCE, p38 MAPK, and TRPV1, we used the p38 MAPK inhibitor (SB203580) to observe whether blocking p38 MAPK could reduce the TRPV1 mRNA level in the PIPN model. Figure $7 \mathrm{f}$ showed that blocking PKC $\varepsilon$ or p38 MAPK could significantly inhibit the mRNA level of TRPV1. In addition, CSBTA was combined with $\mathrm{PKC} \varepsilon$ inhibitor or p38 MAPK inhibitor to confirm the role of CSBTA. However, there were no significant differences in TRPV1 mRNA level between the combination of $50 \mu \mathrm{g} /$ $\mathrm{ml}$ CSBTA and PKCe or p38 MAPK inhibitors and the use of each inhibitor alone. These results suggested that CSBTA probably achieved an analgesic effect by inhibiting PKCE/p38 MAPK/TRPV1 signaling pathway.

\section{Discussion}

Paclitaxel-induced peripheral neuropathy in rats is regarded as an internationally recognized animal model of neuropathic pain. PIPN model produces persistent pain behaviors, including mechanical hyperalgesia and temperature hyperalgesia (heat and cold), which will contribute to elucidate the mechanisms $[6,40]$. In the present study, through intraperitoneal injections of paclitaxel $(2 \mathrm{mg} / \mathrm{kg})$, the mechanical and thermal allodynia and hyperalgesia in rats were changed. As shown in Fig. 2, $30 \mathrm{mg} / \mathrm{kg}$ CSBTA and $120 \mathrm{mg} / \mathrm{kg}$ CSBTA gradually recovered mechanical pain caused by paclitaxel after 2 weeks and eventually normalized. Some studies have shown that paclitaxel could induce thermal hyperalgesia in the PIPN rat model, consistent with clinical hyperalgesia in patients with peripheral neuropathy $[6,41]$. We used a thermal laser instrument and a tail-flick test to detect the heat sensitivity of rats. The results showed that $30 \mathrm{mg} / \mathrm{kg}$ CSBTA and $120 \mathrm{mg} / \mathrm{kg}$ CSBTA could normalize thermal hyperalgesia of the foot and tail. Coldinduced pain is often used as an indicator to measure neuropathic pain behavior in animal models. Detection of cold-induced pain is an important method to study the underlying pathophysiological mechanism of pain. In rodents, there are various methods for detecting coldinduced pain, such as acetone, cold plate experiments, and ethyl chloride spray. Each test has its advantages and disadvantages [42]. In this experiment, we used dry ice to stimulate the feet of rats. The investigation found that $30 \mathrm{mg} / \mathrm{kg}$ CSBTA and $120 \mathrm{mg} / \mathrm{kg}$ CSBTA restored the threshold of cold hyperalgesia in PIPN rats.

TRPV1, one of the nonselective cation channels, could be activated by heat $\left(43{ }^{\circ} \mathrm{C}\right)$, protons, and ligand (e.g., capsaicin) [6, 43]. TRPV1 is transported from DRG along the sciatic nerve to peripheral nerves of the skin and is also transferred from DRG to the dorsal horn of the spinal cord [16]. Hara et al. [7] have confirmed that intraperitoneal injection of paclitaxel could increase TRPV1 in rat plantar skin and sensitize the TRPV1 channel, which is regarded as the cause of heat hyperalgesia. Some studies have shown that intraperitoneal injection of TRPV1 antagonists (such as capsazepine and SB366791) in PIPN animals would attenuate paclitaxel-induced thermal hyperalgesia in a dose-dependent manner but exhibited no pronounced effect on mechanical allodynia [6], further confirming the relationship between TRPV1 and thermal hyperalgesia. Inflammatory states or injection of some cytokines (such as bradykinin and nerve growth factor) could develop into severe thermal hyperalgesia, and TRPV1 ${ }^{-1-}$ mice would provide genetic support for the idea that TRPV1 is a crucial component of inflammation-induced hyperalgesia [44]. In combination with the current animal experiments and relevant clinical studies of pain, we found no particularly appropriate, available, and universally recognized TRPV1 antagonist in the clinical treatment of pain. Therefore, we did not set a positive drug group in the animal part of this experiment. Activation of TRPV1 led to depolarization of neurons and the release of neuropeptides in peripheral and central nerve endings. And then, neuropeptides are coupled with their related receptors and enhance the sensitivity of nociceptors [12]. Excitatory neuropeptides, such as calcitonin gene-related peptides (CGRP), are released from primary afferent nociceptors, which are crucial in initiating and developing pain. It can be recognized as a potential biomarker for the activation of sensory neurons [45]. The increased release of neuropeptides induced by paclitaxel may result in sensitization of primary sensory neurons and subsequently caused mechanical allodynia and tingling in patients [46]. Therefore, we used CGRP mRNA as an indicator to observe the paclitaxel effect on neuronal function.

The increase of PKC expression in DRG was observed in the PIPN mouse model, and inhibition of PKC attenuated paclitaxel-induced chronic neuropathic pain [13]. There are three isoforms of PKC that are co-labeled with 
TRPV1 on nociceptors [6, 45]. Among these isoforms, $\mathrm{PKC} \varepsilon$ is the most important in paclitaxel-induced neuropathy [47]. PKCe, one of the subtypes of PKC, induces intracellular signaling pathways in primary nociceptor receptors and mediates cytokine-induced nociceptor receptors activation. It is responsible for the transition from acute to chronic pain [45]. PKC $\varepsilon$ is also a kind of the second messenger, which mediates paclitaxel-induced hyperalgesia [21]. Recent studies have shown that one of the targets of PKC $\varepsilon$ in peripheral nociceptive signaling is TRPV1 [45, 48-50]. A variety of inflammatory mediators (e.g., ATP, bradykinin, and prostaglandins) could enhance TRPV1 through the PKC-dependent pathway and reduce the temperature threshold of TRPV1 [21]. Activation of $\mathrm{PKC}$, especially $\mathrm{PKC} \varepsilon$, sensitizes nociceptor responses, but PKC inhibitors or mutations can attenuate these responses by disrupting the phosphorylation sites of TRPV1 [51]. Zhang and Mcnaughton proposed that inhibition of plasma-membrane translocation of PKC $\varepsilon$ could also ameliorate paclitaxel-induced peripheral neuropathy $[52,53]$. In addition, TRPV1 activation regulates the excitatory synaptic transmission of sensory synapses, and the activation of PKC can further enhance its effect. This finding provides a potential mechanism that sustained activation of PKC will contribute to hyperalgesia in PIPN [54].

Mitogen-activated protein kinases (MAPK), mediated by p38 rather than ERK, acts on DRG neurons in the pathogenesis of pain [16]. Previous studies have illustrated that $\mathrm{p} 38$ MAPK plays an important role in mechanical allodynia and thermal hyperalgesia after nerve injury, and expression of p-p38 MAPK was elevated in DRG neurons after chronic constriction injury of the sciatic nerve [55-57]. In general, p38 MAPK is a crucial regulator in DRG neurons and spinal cord neurons, involving in the progression of PIPN. TRPV1 is a heat-sensitive receptor in DRG neurons, and its expression is upregulated after sensory nerve damage, related to activation of p38 MAPK in primary sensory neurons [16, 58]. p38 MAPK activation in DRG would enhance the expression of TRPV1 and promote TRPV1 translation and transporting to peripheral sensors, which is helpful to maintain heat hyperalgesia [43]. In addition, the p38 MAPK pathway directly or indirectly activates transcription factors and induces the release of pro-inflammatory cytokines such as TNF- $\alpha$, IL-1 $\beta$, and IL-6 [16]. Studies have found that increased expression of p-p38 MAPK and TRPV1 in the peripheral and central nervous systems is usually accompanied by increased proinflammatory cytokines in the spinal dorsal horn [59]. Ji et al. found that activation of p38 MAPK in the DRG increases TRPV1 levels in nociceptor peripheral terminals and contributes to the maintenance of inflammatory pain [16]. Whereas TRPV1 coexists with p38 MAPK in microglia and excitatory neurons [59], the axonal transport of TRPV1 may be related to the phosphorylation and activation of p38 MAPK in the inflammatory environment. Inhibition of p-p38 MAPK expression can significantly reduce the content of TRPV1 in the neuronal body and skin tissue and alleviate the temperature sensitivity caused by inflammation $[16,60]$. Therefore, thermal nociceptive sensitivity can be regulated via p38 MAPK/ TRPV1 in the peripheral and central nervous systems in physiological and pathological conditions [59, 61].

Paclitaxel does not penetrate the blood-brain barrier and could not accumulate in the central nervous system but will damage the peripheral nervous system, including nerve endings, peripheral nerves, and DRG. Paclitaxel causes damage to the sciatic nerve, nerve endings, and DRG during the development of PIPN [13, 62]. The results showed that $120 \mathrm{mg} / \mathrm{kg}$ CSBTA could effectively inhibit PKCe, p-p38 MAPK, and TRPV1 protein expressions (Fig. 4). Accordingly, paclitaxel increased the level of inflammatory cytokines (such as TNF- $\alpha$, IL-1 $\beta$, and PGE2 in serum and plantar skin supernatant) in PIPN, and CSBTA exhibited significant inhibition on proinflammatory cytokines. In the spinal cord and DRG tissues, gene levels of PGE2, TNF- $\alpha$, CGRP, and SP showed the same situation (Fig. 3). These results are consistent with the published results of CSBTA improving cisplatininduced peripheral neuropathy [25]. According to the in vivo experiments, we found that CSBTA alleviates the inflammatory state by inhibiting PKCe, p-p38 MAPK, and TRPV1 protein levels and affects related behavioral indicators to achieve the purpose of ameliorating PIPN eventually.

DRG is isolated from the blood-brain barrier and is surrounded by rich capillaries, making it highly susceptible to drug neurotoxicity and participating in sensory signal transmission [63]. Although paclitaxel doesn't penetrate the blood-brain barrier, it can accumulate in dorsal root ganglion neurons [64]. The concentration of paclitaxel and CSBTA did not affect cell viability (Fig. 5). Consistent with the data obtained from animal experiments, $50 \mu \mathrm{g} / \mathrm{ml} \mathrm{CSBTA}$ significantly inhibited protein contents of PKC $\varepsilon$, p-p38 MAPK, and TRPV1, and reduced mRNA levels of PGE2, TNF- $\alpha$, and CGRP (Figs. 6 and 7). Interestingly, inhibitors of $\mathrm{PKC \varepsilon}$ reduced cytokines production, suggesting that paclitaxel increased cytokines by activating $\mathrm{PKC} \varepsilon$. Although the inhibitory effect of PKC $\varepsilon$ inhibitors on TRPV1 and PKC $\varepsilon$ protein is stronger than the inhibitory effect of CSBTA, $50 \mu \mathrm{g} / \mathrm{ml}$ CSBTA has a more obvious downregulation of p-p38 MAPK, suggesting that CSBTA has multiple targets.

Previous studies showed that $\mathrm{Ca}^{2+}$-dependent PKCMAPK pathways, including the ERK, JNK, and p38-type 


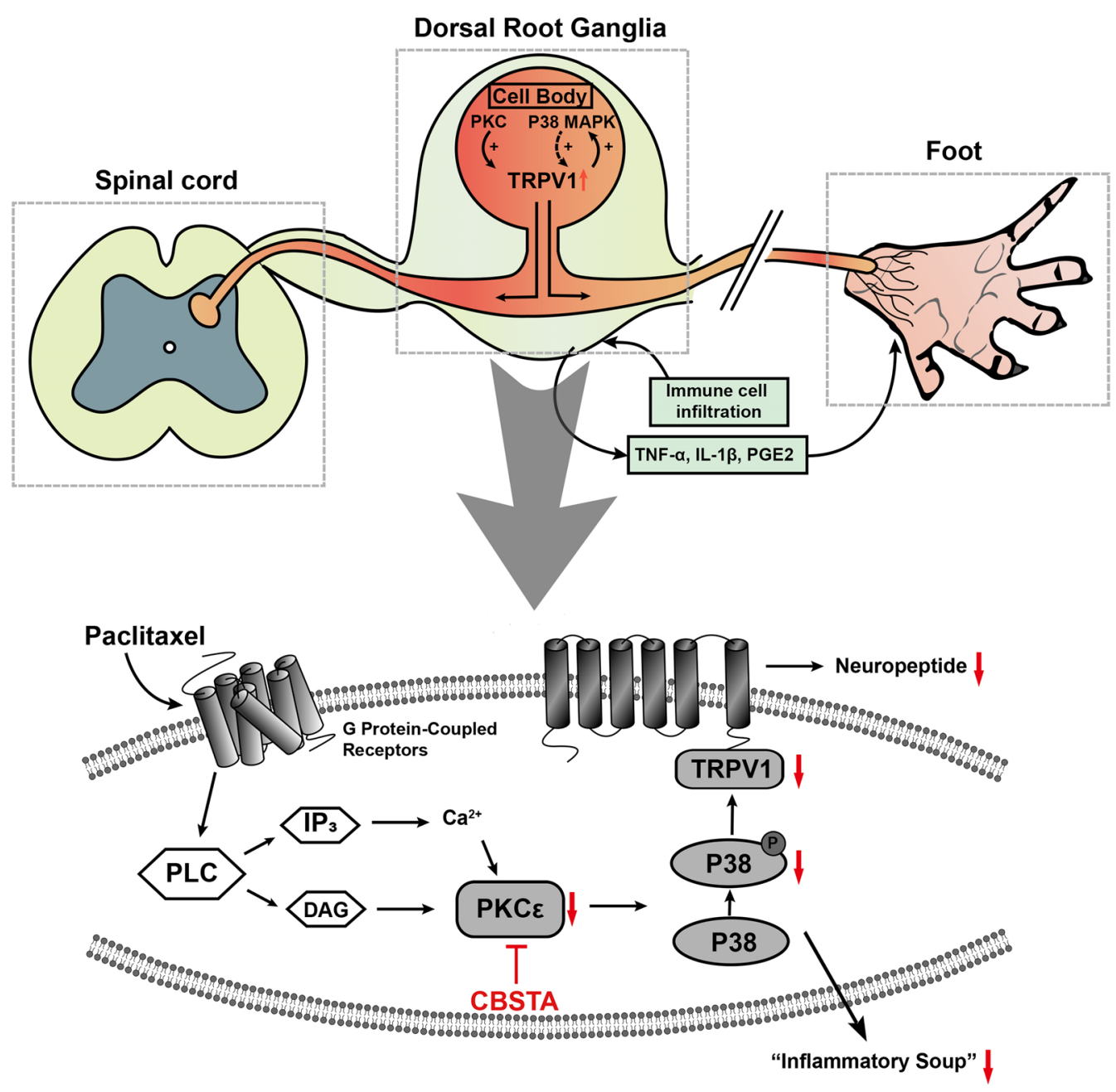

Fig. 8 Schematic summary of CSBTA effect and potential mechanism on PIPN

signaling pathways, participate in cardiac remodeling, visceral leishmaniasis, oxidative stress, immunomodulatory effect, and etc. [65-68] As a downstream molecule of $\mathrm{Ca}^{2+}$-dependent signaling pathways, PKC is a ubiquitous serotonin protein kinase that catalyzes the phosphorylation of many cell proteins [67]. Additionally, the activation of MAPK is recognized as a pathogenic mechanism in chronic pain [69]. In recent years, exploring the multiple functions of signaling pathways and interactions between targets have gradually become a research focus, and PKC/p38 MAPK is no exception. Overall, those studies indicate that $\mathrm{PKC} / \mathrm{p} 38$ MAPK pathway has multiple functions [70,71]. At the same time, numerous studies demonstrated that $\mathrm{PKC}$ is an upstream molecule that regulates the activation of p38 MAPK in the PIPN process $[15,65]$. In combination with the PKCe inhibitor in the PIPN cell model, it could significantly inhibit the protein content of p38 MAPK (Fig. 7b) and reduce the gene expression of inflammatory factors (Fig. 6). Thus, PKC $\varepsilon$ was an upstream molecule of p38 and TRPV1 in PIPN cell models to improve the inflammation state of DRG neurons. Next, we examined whether the p38 MAPK pathway regulates TRPV1 and found that the $\mathrm{p} 38$ inhibitor SB203580 significantly suppressed paclitaxelinduced upregulation of TRPV1 in vitro (Fig. 7f). Previous research mentioned that $\mathrm{p} 38$ activation in small to medium-sized DRG neurons might have a crucial role in the expression of TRPV1 $[16,72]$. Thus, our finding that paclitaxel-induced p38 MAPK has an essential role in the TRPV1 channel is not surprising. In addition, there was no significant difference in TRPV1 expression between CSBTA combined with SB203580 and SB203580 alone. In addition, there was no significant difference in TRPV1 mRNA level between the combination of CSBTA and 
staurosporine and staurosporine alone. Our data suggested that CSBTA probably achieved an analgesic effect by inhibiting PKCe/p38 MAPK/TRPV1 signaling pathway (Fig. 8).

\section{Conclusions}

Overall, CSBTA effectively improved behavioral indexes of mechanical and thermal allodynia and hyperalgesia and regulated the contents of pro-inflammatory cytokines (such as IL-1 $\beta$, TNF- $\alpha$, PGE2) and neuropeptides (SP and CGRP) in different tissues in vivo. We concluded that CSBTA could ameliorate pain behavior and the inflammatory status of PIPN. CSBTA decreased relevant protein expressions in $\mathrm{PKC} / \mathrm{p} 38$ MAPK/TRPV1 signaling pathway in the spinal cord and DRG of PIPN rats and primary DRG neurons (Fig. 8). Therefore, CSBTA has a perspective therapeutic effect on the treatment of paclitaxel-induced peripheral neuropathy.

\section{Abbreviations}

CGRP: Calcitonin gene-related peptide; CIPN: Chemotherapy-induced peripheral neuropathy; CSBTA: Corydalis saxicola Bunting total alkaloids; DRG: Dorsal root ganglion; IL-1 $\beta$ : Interleukin-1 $\beta$; PGE2: Prostaglandin E2; PIPN: Paclitaxelinduced peripheral neuropathy; PKC $\varepsilon$ : Protein kinase C $\varepsilon$; SP: Substance P; TNFa: Tumor Necrosis Factor-a; TRPV1: Transient receptor potential vanilloid 1.

\section{Acknowledgements}

Not applicable.

\section{Authors' contributions}

CX: Conceptualization, visualization, investigation, methodology, writingoriginal draft, Writing - review \& editing. SL: Formal analysis, visualization. JHu: Conceptualization, investigation, methodology. JHuang: Methodology, visualization. HL: Formal analysis, writing —review \& editing. ZQ: Methodology, software, validation, resources, supervision. FH: Conceptualization, resources, data curation, writing — review \& editing, supervision, Project administration, funding acquisition. All authors read and approved the final manuscript.

\section{Funding}

This work was supported by the "National Science and Technology Major Project" from Ministry of Science and Technology of the People's Republic of China (Grant Number 2017ZX09301026).

\section{Availability of data and materials}

Not applicable.

\section{Declarations}

Ethics approval and consent to participate

The study was conducted according to the ethical guidelines and approved by the Ethics Committee on Laboratory Animal Management of China Pharmaceutical University.

\section{Consent for publication}

We declare that the Publisher has the Author's permission to publish the relevant contribution.

\section{Competing interests}

The authors declare no competing conflict of interests.

\section{Author details}

${ }^{1}$ Jiangsu Key Laboratory of TCM Evaluation and Translational Research, Department of Pharmacology of Chinese Materia Medica, China Pharmaceutical University, 639 Longmian Road, Nanjing 211198, China. ${ }^{2}$ Shenzhen Pingle Orthopedic Hospital (Shenzhen Pingshan Traditional Chinese Medicine Hospital), Shenzhen 518001, China.

Received: 16 March 2021 Accepted: 11 July 2021

Published online: 19 July 2021

\section{References}

1. Duggett NA, Griffiths LA, Flatters SJL. Paclitaxel-induced painful neuropathy is associated with changes in mitochondrial bioenergetics, glycolysis and an energy deficit in dorsal root ganglia neurons. Pain. 2017;158(8):1499-508.

2. Zhang H, Boyette-Davis JA, Kosturakis AK, Li Y, Yoon SY, Walters ET. Induction of monocyte chemoattractant protein-1 (MCP-1) and its receptor CCR2 in primary sensory neurons contributes to paclitaxel-induced peripheral neuropathy. J PAIN. 2013;14(10):1031-44.

3. Xie JD, Chen SR, Pan HL. Presynaptic N-Methyl-D-aspartate (NMDA) receptor activity is increased through protein kinase $C$ in paclitaxel-induced neuropathic pain. J Biol Chem. 2016;291(37):19364-73.

4. Sisignano M, Baron R, Scholich K, Geisslinger G. Mechanism-based treatment for chemotherapy-induced peripheral neuropathic pain. Nat Rev Neurol. 2014;10(12):694-707.

5. Ba XY, Wang JL, Zhou SY, Luo XX, Peng Y, Yang SM, Hao Y, Jin GY. Cinobufacini protects against paclitaxel-induced peripheral neuropathic pain and suppresses TRPV1 up-regulation and spinal astrocyte activation in rats. Biomed Pharmacother. 2018;108:76-84.

6. Chen Y, Yang C, Wang ZJ. Proteinase-activated receptor 2 sensitizes transient receptor potential vanilloid 1 , transient receptor potential vanilloid 4, and transient receptor potential ankyrin 1 in paclitaxel-induced neuropathic pain. Neuroscience. 2011;193:440-51.

7. Hara T, Chiba T, Abe K, Makabe A, Ikeno S, Kawakam K. Effect of paclitaxel on transient receptor potential vanilloid 1 in rat dorsal root ganglion. Pain. 2013;154(6):882-9.

8. Li Y, Adamek P, Zhang H, Tatsui CE, Rhines LD, Mrozkova P, Dougherty PM. The cancer chemotherapeutic paclitaxel increases human and rodent sensory neuron responses to TRPV1 by activation of TLR4. J Neurosci. 2015;35(39):13487-500.

9. Julius D. TRP channels and pain. Annu Rev Cell Dev Biol. 2013;29(1):355-84

10. Szallasi A, Sheta M. Targeting TRPV1 for pain relief: limits, losers and laurels. Expert Opin Investig Drugs. 2012;21(9):1351-69.

11. Szolcsányi J, Pintér E. Transient receptor potential vanilloid 1 as a therapeutic target in analgesia. Expert Opin Ther Targets. 2013;17(6):641-57.

12. Quartu M, Carozzi VA, Dorsey SG, Serra MP, Marmiroli P. Bortezomib treatment produces nocifensive behavior and changes in the expression of TRPV1, CGRP, and substance P in the Rat DRG, spinal cord, and sciatic nerve. Biomed Res Int. 2014;14:180428.

13. Kee KH, Seon-Hee H, Salahadin A. Tempol ameliorates and prevents mechanical hyperalgesia in a rat model of chemotherapy-induced neuropathic pain. Front Pharmacol. 2017;7:532.

14. Dina OA, Chen X, Reichling D. Role of protein kinase C. Neuroscience. 2001;108(3):507-15.

15. Schönwasser DC, Marais RM, Marshall CJ, et al. Activation of p38 MAPK in primary afferent neurons kinase/extracellular signal-regulated kinase pathway by conventional, novel, and atypical protein kinase C isotypes. Mol Cell Biol. 1998;18(2):790-801.

16. Ji RR, Samad TA, Jin SX, Schmoll R, Wool CJ. p38 MAPK activation by NGF in primary sensory neurons after inflammation increases TRPV1 levels and maintains heat hyperalgesia. Neuron. 2002;36(1):57-68.

17. Asih PR, Prikas E, Stefanoska K, et al. Functions of p38 MAP kinases in the central nervous system. Front Mol Neurosci. 2020;8(13):570586.

18. Giraud F, Pereira E, Anizon F, et al. Recent Advances in pain management: relevant protein kinases and their inhibitors. Molecules. 2021;26(9):2696.

19. Itoh Y, Sendo T, Hirakawa T, et al. Pemirolast potently attenuates paclitaxel hypersensitivity reactions through inhibition of the release of sensory neuropeptides in rats. Neuropharmacology. 2004;46(6):888-94. 
20. Li Y, Zhang HM, et al. MAPK signaling downstream to TLR4 contributes to paclitaxel-induced peripheral neuropathy. Brain Behav Immun. 2015;49:S0889159115001543.

21. Numazaki M, Tominaga T, Toyooka H, Tominaga M. Direct phosphorylation of capsaicin receptor VR1 by protein kinase $C \varepsilon$ and identification of two target serine residues. J Biol Chem. 2002;277(16):13375-8.

22. Yu JJ, Liu QY, Lu XY, Li XN, Li N, Liu BL, Huang F, Qiu ZX. Inhibitory and inductive effects of Corydalis saxicola Bunting total alkaloids (CSBTA) on cytochrome P450s in rats. Phytother Res. 2018;32(9):1818-27.

23. Wu Y, Lu TL, Ji D, Zhou Y, Mao CQ. Isolation and structural identification of alkaloids from Corydalis saxicola. J Nanjing Univ TCM. 2015;1:81-3.

24. Cheng XX, Wang DM, Jiang $L$, Yang D. Simultaneous determination of eight bioactive alkaloids in Corydalis saxicola by high-performance liquid chromatography coupled with diode array detection. Phytochem Anal. 2008;19(5):420-8.

25. Kuai CP, JuL J, Hu PP, Huang F. Corydalis saxicola alkaloids attenuate cisplatin-induced neuropathic pain by reducing loss of IENF and blocking TRPV1 activation. Am J Chin Med. 2020:48(2):407-28.

26. Ju LJ, Hu PP, Chen P, Wu JJ, Li ZQ, Qiu ZX, Cheng J, Huang F. Corydalis saxicola Bunting total alkaloids attenuate Walker 256-induced bone pain and osteoclastogenesis by suppressing RANKL-induced NF-KB and c-Fos/ NFATc1 pathways in rats. Front Pharmacol. 2021;26(11):609119.

27. Gao W, Zan Y, Wang ZJ, Hu XY, Huang F. Quercetin ameliorates paclitaxelinduced neuropathic pain by stabilizing mast cells, and subsequently blocking PKCE-dependent activation of TRPV1. Acta Pharmacol Sin. 2016;37(9):1166-77.

28. Li YY, Yin CY, Li XJ. Electroacupuncture alleviates paclitaxel-induced peripheral neuropathic pain in rats via suppressing TLR4 signaling and TRPV1 upregulation in sensory neurons. Int J Mol Sci. 2019;20(23):5917.

29. Nataliia K, Mickael D, Dita S-K. Losartan attenuates neuroinflammation and neuropathic pain in paclitaxel-induced peripheral neuropathy. J Cell Mol Med. 2020;24(14):7949-58.

30. Chaplan SR, Bach FW, Pogrel JW, Chung JM, Yaksh TL. Quantitative assessment of tactile allodynia in the rat paw. J Neurosci Methods. 1994;53(1):55-63.

31. Brenner DS, Golden JP, Vogt SK. A simple and inexpensive method for determining cold sensitivity and adaptation in mice. J Vis Exp. 2015;17(97):52640.

32. Hu PP, Huang F. Yunnan Baiyao ameliorates MIA-induced knee osteoarthritis pain in rats through anti-inflammatory effect. Chin J Clin Pharm Therap. 2019;3:254-9.

33. Chinese Pharmacopoeia. 2015. Vol. I.

34. Zhou FQ. Genetic study of axon regeneration with cultured adult dorsal root Ganglion Neurons. J Vis Exp. 2012;66:e4141.

35. Zhu JC, Li Y, Liang JH, Li JX, Huang K, Li J, Liu CY. The neuroprotective effect of oxytocin on vincristine-induced neurotoxicity in mice. Toxicol Lett. 2021;340:67-76.

36. Qiu ZX, Dong JJ, Xue C, Li XN, Liu K, Liu BL, Cheng J, Huang F. Liuwei Dihuang pills alleviate the polycystic ovary syndrome with improved insulin sensitivity through PI3K/Akt signaling pathway. J Ethnopharmacol. 2020;250:111965.

37. Myers RR, Campana WM, Shubayev VI. The role of neuroinflammation in neuropathic pain: mechanisms and therapeutic targets. Drug Discov Today. 2006;11(1-2):8-20.

38. Ma W, Eisenach JC. Intraplantar injection of a cyclooxygenase inhibitor ketorolac reduces immunoreactivities of substance $p$, calcitonin generelated peptide, and dynorphin in the dorsal horn of rats with nerve injury or inflammation. Neuroscience. 2003;121(3):681-90.

39. Chiba T, Oka Y, Kambe T, Koizumi N, Abe K, Kawakami K, Utsunomiya I, Taguchi K. Paclitaxel-induced peripheral neuropathy increases substance $P$ release in rat spinal cord. Eur J Pharmacol. 2016;770:46-51.

40. Jia M, Wu C, Gao F. Activation of NLRP3 inflammasome in peripheral nerve contributes to paclitaxel-induced neuropathic pain. Mol Pain. 2017;13:1744806917719804

41. Sałat K, Cios A, Wyska E. Antiallodynic and antihyperalgesic activity of 3-[4-(3-trifluoromethyl-phenyl)-piperazin-1-yl]-dihydrofuran-2-one compared to pregabalin in chemotherapy-induced neuropathic pain in mice. Pharmacol Biochem Behav. 2014;122:173-81.

42. Vissers K, Meert T. A behavioral and pharmacological validation of the acetone spray test in gerbils with a chronic constriction injury. Anesth Analg. 2005;101(2):457-64.
43. Wang Y, Gao Y, Tian Q, Deng Q, Wang Y, Zhou T. TRPV1 SUMOylation regulates nociceptive signaling in models of inflammatory pain. Nat Commun. 2018;9(1):1529-35.

44. Caterina MJ. Impaired nociception and pain sensation in mice lacking the Capsaicin Receptor. Science. 2000;288(5464):306-13.

45. He Y, Wang ZJ. Nociceptor Beta II, Delta, and Epsilon isoforms of PKC differentially mediate paclitaxel-induced spontaneous and evoked pain. J Neurosci. 2015;35(11):4614-25.

46. Dougherty PM, Cata JP, Cordella JV, Burton A, Weng HR. Taxol induced sensory disturbances characterized by preferential impairment of myelinated fiber function in cancer patients. Pain. 2004;109(1-2):132-42.

47. Blaker AL, Mitchell CM, Semple EA. Identifying the role of novel protein kinase $C$ isoforms in mediating paclitaxel-induced peripheral neuropathy. J Neurosci. 2015;35(28):10101-12.

48. Yamamoto H, Kawamata T, Ninomiya T, Omote K, Namiki A. Endothelin-1 enhances capsaicin-evoked intracellular $\mathrm{Ca} 2+$ response via activation of endothelin a receptor in a protein kinase $C \varepsilon$-dependent manner in dorsal root ganglion neurons. Neuroscience. 2006;137(3):949-60.

49. Khasar SG, Lin YH, Martin A, Dadgar J, McMahon T, Dan W. A novel nociceptor signaling pathway revealed in protein kinase $C \varepsilon$ mutant mice. Neuron. 1999;24(1):253-60.

50. Hucho TB, Dina OA, Kuhn J, Levine JD. Estrogen controls PKC $\varepsilon$ dependent mechanical hyperalgesia through direct action on nociceptive neurons. Eur J Neurosci. 2006;24(2):527-34.

51. Wang Y, Gao Y, Tian Q, et al. TRPV1 SUMOylation regulates nociceptive signaling in models of inflammatory pain. Nat Commun. 2018;9(1):1529.

52. Zhang $X$, Mcnaughton PA. Why pain gets worse: the mechanism of heat hyperalgesia. J Gen Physiol. 2006;128(5):491-3.

53. Honda K, Shinoda M, Kondo M, et al. Sensitization of TRPV1 and TRPA via peripheral mGluR5 signaling contributes to thermal and mechanical hypersensitivity. Pain. 2017;1:1754-64.

54. Sikand P, Premkumar LS. Potentiation of glutamatergic synaptic transmission by protein kinase C-mediated sensitization of TRPV1 at the first sensory synapse. J Physiol. 2007:581(2):631-47.

55. Schäfers $\mathrm{M}$, Svensson $\mathrm{Cl}$, Sommer $\mathrm{C}$, et al. Tumor necrosis factor-alpha induces mechanical allodynia after spinal nerve ligation by activation of p38 MAPK in primary sensory neurons. J Neurosci. 2003;23(7):2517-21.

56. Svensson Cl, Marsala M, Westerlund A, et al. Activation of p38 mitogenactivated protein kinase in spinal microglia is a critical link in inflammation-induced spinal pain processing. J Neurochem. 2003:86(6):1534-44.

57. Chaumette T, Delay L, Barbier J, et al. c-Jun/p38MAPK ASIC3 pathways specifically activated by nerve growth factor through TrkA are crucial for mechanical allodynia development. Pain. 2020;161(5):1109-23.

58. Facer P, Casula MA, Smith GD, et al. Differential expression of the capsaicin receptor TRPV1 and related novel receptors TRPV3, TRPV4 and TRPM8 in normal human tissues and changes in traumatic and diabetic neuropathy. BMC Neurol. 2007;23(7):11.

59. Sun L, Li H, Tai LW, et al. Adiponectin regulates thermal nociception in a mouse model of neuropathic pain. Br J Anaesth. 2018;120(6):1356-67.

60. Amantini C, Mosca M, Nabissi M, et al. Capsaicin-induced apoptosis of glioma cells is mediated by TRPV1 vanilloid receptor and requires p38 MAPK activation. J Neurochem. 2007;102(3):977-90.

61. Miyagawa YI, Kobayashi K, Yamanaka H, et al. Peripherally increased artemin is a key regulator of TRPA1/N1 expression in primary afferent neurons. Mol Pain. 2015:8(11):8.

62. Nishida T, Tsubota M, Kawaishi Y, Yamanishi H, Kamitani N, Sekiguchi F, Ishikura H, Liu K, Nishibori M, Kawabata A. Involvement of high mobility group box 1 in the development and maintenance of chemotherapyinduced peripheral neuropathy in rats. Toxicology. 2016;365:48-58.

63. Lees JG, Makker PGS, Tonkin RS. Immune-mediated processes implicated in chemotherapy-induced peripheral neuropathy. Eur J Cancer. 2017:73:22-9.

64. Hana S, Irina V. Pathophysiology of chemotherapy-induced peripheral neuropathy. Front Mol Neurosci. 2017;10:174.

65. Wu GJ, Wang ZX, Shan PR, et al. Suppression of Netrin-1 attenuates angiotension II-induced cardiac remodeling through the PKC/MAPK signaling pathway. Biomed Pharmacother. 2020;130:110495. 
66. Mamilla RC, Amrita K, Sujatha S, et al. Oral administration of eugenol oleate cures experimental visceral leishmaniasis through cytokines abundance. Cytokine. 2021;145:155301.

67. Pu YW, Liu ZJ, Tian $\mathrm{H}$, et al. The immunomodulatory effect of Poria cocos polysaccharides is mediated by the $\mathrm{Ca} 2+/ \mathrm{PKC} / \mathrm{p} 38 / \mathrm{NF}-\mathrm{KB}$ signaling pathway in macrophages. Int Immunopharmacol. 2019;72:252-7.

68. $X u B Y$, Tang XD, Chen J, et al. Rifampicin induces clathrin-dependent endocytosis and ubiquitin-proteasome degradation of MRP2 via oxidative stress-activated PKC-ERK/JNK/p38 and PI3K signaling pathways in HepG2 cells. Acta Pharmacol Sin. 2020;41(1):56-64.

69. Sun L, Wang GD, He MF, et al. Effect and mechanism of the CACNA2D1CGRP pathway in osteoarthritisinduced ongoing pain. Biomed Pharmacother. 2020;129:110374.

70. Ye L, Hong F, Ze X, et al. Toxic effects of $\mathrm{TiO} 2$ nanoparticles in primary cultured rat sertoli cells are mediated via a dysregulated $\mathrm{Ca} 2+/ \mathrm{PKC} / \mathrm{p} 38$ MAPK/NF-kB cascade. J Biomed Mater Res. 2017;105(5):1374-82.
71. Park J, Kim SH, Cho D, Kim TS. Formononetin, a phytooestrogen, and its metabolites up-regulate interleukin-4 production in activated T cells via increased AP-1 DNA binding activity. Immunology. 2005;116(1):71-81.

72. Mizushima T, Obata K, Yamanaka H, et al. Activation of p38 MAPK in primary afferent neurons by noxious stimulation and its involvement in the development of thermal hyperalgesia. Pain. 2005;113(1-2):51-60.

\section{Publisher's Note}

Springer Nature remains neutral with regard to jurisdictional claims in published maps and institutional affiliations.
Ready to submit your research? Choose BMC and benefit from:

- fast, convenient online submission

- thorough peer review by experienced researchers in your field

- rapid publication on acceptance

- support for research data, including large and complex data types

- gold Open Access which fosters wider collaboration and increased citations

- maximum visibility for your research: over 100M website views per year

At BMC, research is always in progress.

Learn more biomedcentral.com/submissions 